\title{
Marketing Concept Manifestations in Fiji Enterprises: Confirming the Link to Organizational Competitiveness
}

\author{
Stern Neill \\ Raghuvar Dutt Pathak \\ Narendra Reddy
}

\begin{abstract}
This paper proposes an integrative view of the marketing concept (i.e., the ability to understand and satisfy customers) and examines its prevalence and effect on competitiveness in organizations operating in an isolated and less economically developed country. The marketing concept manifests as marketing expertise, market orientation, and externally directed organizational values. Based on a sample of 86 firms operating in Fiji, the results indicate that these three mechanisms promote organizational competitiveness, thus supporting the universality of the marketing concept. These findings confirm the important role of the marketing concept in the competitiveness of firms in a less developed economy.
\end{abstract}

KEYWORDS. Marketing concept, organizational competitiveness, marketing expertise, market orientation, organizational values, Fiji

The marketing concept maintains that a principal means to sustained organizational competitiveness is through the application of superior knowledge and skills in satisfying customers. Research on this concept has been directed at the role of market orientation on firm performance-particularly within developed economies (cf., Kirca et al., 2005). The marketing concept is critical to the long-run success of organizations, including those in developing economies (Shultz \& Pecotich, 1997); and yet, research has thus far been limited to a few studies on emerging economies in Asia and Central Europe (e.g., Bhuian, 1998; Deshpandé \& Farley, 2004; Liu et al., 2003; Subramanian \& Gopalakrishna, 2001) to the near exclusion of studies in less economically developed countries. The first objective of this paper is to examine the effect of the marketing concept on the competitiveness of firms operating in an isolated and less economically developed country. Given that research has focused on developed and emerging economies, the results should broaden our understanding and serve to test the rigor of the marketing concept.

The second objective of this study is to assume a more integrative view of the marketing concept. The marketing concept entails both behavioral and cultural components. The behavioral aspects have been the focus of much attention, particularly relating to the processing of market intelligence (e.g., Kohli \& Jaworski,

Stern Neill is an Associate Professor at the Orfalea College of Business, California Polytechnic State University, San Luis Obispo, CA, USA. Raghuvar Dutt Pathak is a Professor at the School of Management and Public Administration, Faculty of Business and Economics, The University of the South Pacific, Suva, Fiji Islands. Narendra Reddy is an Associate Professor at the School of Management and Public Administration, Faculty of Business and Economics, The University of the South Pacific, Suva, Fiji Islands. 
1990). Extending this behavioral component, Day (1994) identifies specialized marketing capabilities (i.e., knowledge and skills) that represent the marketing concept. Recently, studies have begun to elaborate on these capabilities (e.g., Vorhies \& Morgan, 2005). Research on the cultural manifestations of the marketing concept has examined the beliefs and values of managers (e.g., Deshpandé \& Farley, 2004; Deshpandé et al., 1993; Narver \& Slater, 1990). Building on both streams of research, this paper examines the marketing concept as manifested in organizational expertise, beliefs, and values and analyzes each mechanism's effect on competitiveness.

\section{CONCEPTUAL MODEL}

Organizations that maintain a marketing concept are better able to understand and respond to market demands and thus sustain a competitive advantage. Competitiveness is achieved through the effective configuration and utilization of resources in order to deliver value that is perceived by customers as significant and superior to that of the competition (Day, 1994; Porter, 1990). This study proposes that organizational competitiveness can be achieved through realization of the marketing concept. The marketing concept manifests as learned patterns based on past interactions with the market. As such, it is a product of the organization's memory, which is information about past successes and failures that is retained and may affect future firm response (Walsh \& Ungson, 1991). The marketing concept, as collective memory, enables the firm to better understand and respond to market demands and thus to sustain a competitive advantage. This study examines the effect of the marketing concept in terms of three aspects of the organization's memory: expertise, beliefs, and values.

These three mechanisms are deeply rooted within the firm. Marketing expertise is the accumulation of marketing knowledge and skills that have proven effective. A market orientation consists of beliefs that place an emphasis on the market as the means for firm success (Deshpandé et al., 1993). Organizational values are preferences for certain behaviors or outcomes (Trice $\&$ Beyer, 1993). A firm that instills the marketing concept maintains values that are externally directed. Both a market orientation and externallydirected values are components of the organization's culture, which is retained as a means of coordination and adaptation (Schein, 1992). Thus, a firm's marketing expertise, market orientation, and values are products of the past-learned through past interactions with the market. As illustrated in Figure 1, this study posits that each of these mechanisms represents a key aspect of the marketing concept as demonstrated through their effects on organizational competitiveness.

\section{Marketing Expertise}

Experienced firms are better able to develop, integrate, and deploy internal and external

FIGURE 1. The Marketing Concept and Organizational Competitiveness

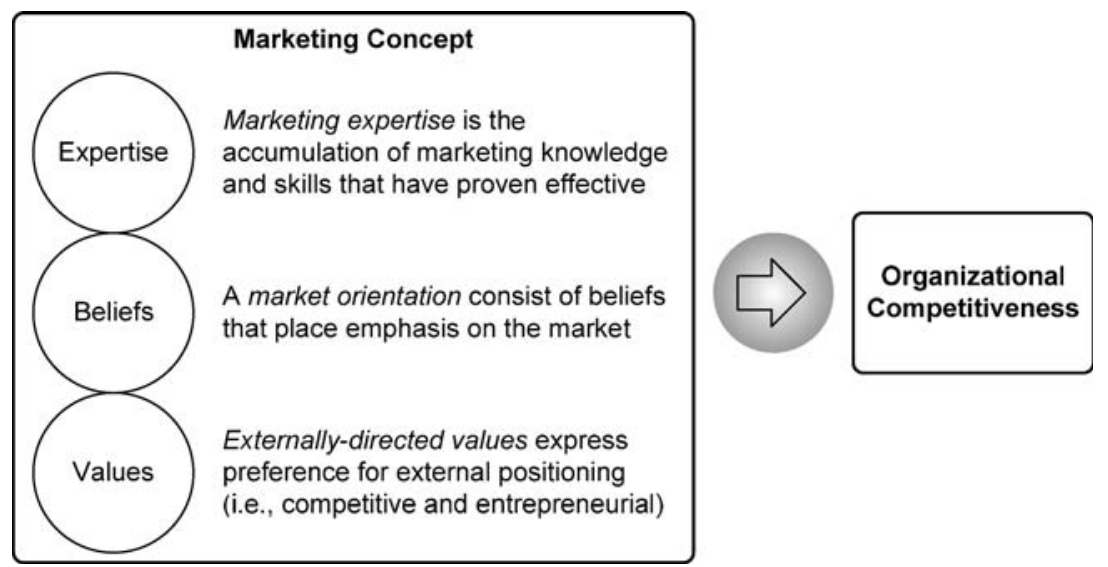


resources (Zollo \& Winter, 2002). Expertise is composed of knowledge and skills in a particular area. Knowledge provides the collective insight about what worked and why (Day, 1994), while skills enable the application of that knowledge towards successful ends. Firms with marketing expertise have learned that the key to organizational success is through the application of marketing knowledge and skills directed at satisfying customers better than competitors. Such firms have retained the marketing lessons of past successes and failures and thus have realized the marketing concept. This accumulation of marketing experience allows firms to achieve a higher degree of organizational competitiveness. Given Fiji's developing context, marketing capabilities may function at a premium providing the experienced firm with an increased competitive advantage.

$\mathrm{H}_{1}$ : Marketing expertise is positively related to organizational competitiveness.

\section{Market Orientation}

Organizations with a market orientation maintain the belief that the key to organizational success is through the satisfaction of customers. Deshpandé and Farley (2004) have demonstrated that those organizations that place the interests of the customer first achieve superior performance. The authors demonstrate that this positive relationship is particularly strong in nonindustrialized nations. Firms that maintain a market orientation have learned that success is based on the firm's ability to apply its customer focus in the deployment of marketing resources from which customers benefit. This belief is consistent with the marketing concept and should have a favorable impact on the firm's competitiveness. The effect should be particularly evident in developing economies, such as Fiji. Thus, maintaining a market orientation should translate more readily into organizational competitiveness.

$\mathrm{H}_{2}$ : A market orientation is positively related to organizational competitiveness.

\section{Organizational Values}

Organizational values shape interpretations and thus are fundamental to how the firm engages its environment. For this study, organizational values are operationalized using the competing values model (Quinn \& Rohrbaugh, 1983). This model captures the extent to which values vary along two dimensions-externalinternal and formal-informal-resulting in four value types with the following labels (Deshpandé \& Farley, 2004):

Competitive: emphasis on competitive advantage and market superiority

Entrepreneurial: emphasis on innovation and risk-taking

Bureaucratic: emphasis on regulations and formal structures

Consensual: emphasis on loyalty, tradition, and internal maintenance

Organizations maintain a mixture of these values. Based on a series of studies, Deshpandé and Farley (2004) chronicle the direct effect of each value type on firm performance. The authors report a tendency for externally oriented values (i.e., competitive and entrepreneurial) to outperform more internally oriented values (i.e., bureaucratic and consensual). In particular, firms that maintain externally directed values (i.e., competitive and entrepreneurial) have learned that success is a product of adaptation to market forces. This study seeks to confirm that there is a positive relationship between more externally focused values and organizational competitiveness by examining firms operating in Fiji.

H3: Externally-directed organizational values (i.e., competitive and entrepreneurial) are positively related to organizational competitiveness.

\section{METHODOLOGY}

\section{Background on Enterprises in Fiji}

Fiji presents its own, unique socio-political context in which to explore the marketing 
concept's role on competitiveness. Fiji is an island nation with finite resources. In the country's first 15 years after independence from Great Britain in 1970, it was considered "a postcolonial success" (Emmott, 1985); however, after successive political coups and continuing land rights issues, the nation has experienced sharp economic declines marked by periods of negative gross domestic product, emigration of professional and skilled labor, and a loss of investor confidence due to an uncertain business climate (Reddy, 2004). Currently, the economy ranks 143rd in terms of gross domestic product (International Monetary Fund, 2007); the World Bank classifies the country as lower middle income with annual per capita income less than \$3,595US (World Bank, 2007); and the United Nation's Human Development Index ranks Fiji 90th in terms of life expectancy, educational attainment, and adjusted real income (United Nations Development Programme, 2006). The national culture in Fiji is best described as hierarchal in that there tends to be ascribed roles that reinforce unequal distribution of power and resources (Schwartz 2004). Given both its developing context and the degree of social and economic turbulence Fiji provides an opportunity to test the robustness of marketing theory.

Organizational research in Fiji has primarily relied on case studies (e.g., Baldacchino, 2000; Hailey, 1985; Qalo, 1997; Reddy, 2001) thatwhile rich in detail and informative of theorylack the generalizabilty of a broader sampling strategy. Empirical data are limited and offer mostly descriptive accounts of enterprises in Fiji rather than exploring the causal mechanisms for organizational competitiveness. A notable exception, of particular relevance to this study, finds the strategies of failed entrepreneurs in Fiji to be more reactive and less goal-oriented (Van Gelder et al., 2007). Unexamined are the characteristics that explain the success of Fiji enterprises.

\section{Data Collection and Measurement}

To test the hypotheses, multi-item scales were used. The scales were either validated in prior studies or adapted for this study. Prior to data collection, two expert judges who were both familiar with local customs and had previously conducted research with managers in Fiji reviewed the instrument; however, translation was unnecessary as the official language is English. Appendix 1 contains the items for this study's measures including source and content.

Data were gathered by surveying managers from a variety of industries using a postal mailing of 238 survey instruments. Each respondent acted as a key informant for his/her organization by reporting on the business as a whole. To be included in the study, respondents had to hold a management level position. Given these requirements, nine respondents were removed from the study, leaving 86 usable responses. The remaining informants represented a mix of industries (44\% personal and community services, $16 \%$ financial and communication services, $14 \%$ wholesale/retail trade, $10 \%$ transportation, $8 \%$ manufacturing, and $8 \%$ other). Respondents were executives ( $40 \%$ general manager/CEO, $13 \%$ deputy general manager, and $47 \%$ middle management) and were considerably involved in strategic decisions (average of 5.4 on a 7 -point scale).

\section{RESULTS}

For organizational competitiveness, marketing expertise, and market orientation, unidimensionality was assessed by examining the interrelations among each reflective scale's items using item-to-scale correlations, exploratory factor analysis, and Cronbach's alpha. Item-to-scale correlations were examined for each construct to assess that all items exceeded .40. Each measure was then subjected to exploratory factor analyses to ensure that all items loaded on the first factor, which was confirmed in each case. No items were removed based on this analysis. Finally, Cronbach's alphas were calculated to gauge the reliability of the individual constructs. All scales exhibited acceptable reliabilities.

The competing values measure is comprised of formative indicators; thus, unidimensionality is not assumed (cf., Netemeyer et al., 
TABLE 1. Scale Reliabilities and Descriptive Statistics

\begin{tabular}{lccc}
\hline Construct & Reliability & Mean & Standard Deviation \\
\hline Organizational & & & \\
Competitiveness & .95 & 4.67 & 1.48 \\
Marketing expertise & .92 & 5.31 & 1.17 \\
Market orientation & .92 & 5.08 & 1.23 \\
$\quad$ Competing values & & & \\
$\quad$ Competitive & - & 80.18 & 32.79 \\
$\quad$ Entrepreneurial & - & 80.05 & 38.76 \\
$\quad$ Bureaucratic & - & 132.53 & 49.15 \\
$\quad$ Consensual & - & 107.24 & 45.99 \\
\hline
\end{tabular}

2003). As the measure is a constant-sum among four categories (competitive, entrepreneurial, bureaucratic, and consensual), the four resulting measures are ipsative, requiring that one measure (i.e., bureaucracy) be omitted from the analysis in order to test the effect of the other three values (cf., White et al., 2003). Table 1 presents descriptive statistics and scale reliabilities.

To test the hypotheses, a multiple regression equation was estimated. Table 2 contains the results of the analysis. To control for the influence of foreign investment, a dummy variable was included to account for full or partial foreign ownership. In support of hypothesis 1 , there is a significant positive relationship between marketing expertise and organizational competitiveness $(b=.32$; $p<.01)$. The results also provide support for hypothesis 2, indicating a market

\section{TABLE 2. Regression Results of Standardized Estimates}

\begin{tabular}{lcc}
\hline Independent Variables & Beta & $t$-value \\
\hline Marketing expertise & $.32^{*}$ & $(2.86)$ \\
Market orientation & $.41^{*}$ & $(3.66)$ \\
Consensual & .10 & $(0.98)$ \\
Competitive & $.20^{\star *}$ & $(2.00)$ \\
Entrepreneurial & $.22^{* *}$ & $(2.36)$ \\
Foreign influence & .15 & $(1.80)$ \\
& & \\
Adjusted $R^{2}$ & .59 & \\
$F$-value & $16.33^{*}$ & \\
\hline
\end{tabular}

Note. ${ }^{*} p<.01,{ }^{* \star} p<.05$. orientation is positively and significantly related to organizational competitiveness $(b=.41 ; p<.01)$. Both external-directed competing values increase a firm's competitiveness, supporting hypothesis 3 (competitive $b=.20 ; p<.05$; entrepreneurial $b=.22$; $p<.05)$.

\section{DISCUSSION}

Domestic competitiveness is based on the identification and cultivation of home-based advantages that are developed at the level of the firm (Porter, 1990). These advantages are dependent on the application of the marketing concept which is an intermix of organizational expertise, beliefs, and values that ultimately translate into loyal local markets and thus create barriers to entry aimed at foreign rivals. The study confirms that marketing expertise, beliefs, and values have independent effects on organizational competitiveness. As the results indicate, the marketing concept translates into market-based advantages. Given the social complexity and inimitability of these three mechanisms (Teece et al., 1997), firms following the marketing concept sustain a unique advantage that keeps competitors off balance. By testing these effects in a developing economy, the robustness of the marketing concept is confirmed.

Organizations must maintain the ability to develop, integrate, and deploy marketing resources in the attainment of a sustainable advantage. Adhering to the marketing concept provides a path to competitiveness through better alignment with the marketplace. This study's results provide some clues as to how managers might institutionalize the marketing concept within their organizations. Specifically, organizations must accumulate knowledge and skills that are positioned accordingly and instill the belief that success is derived from the market. The results indicate that firms experienced in marketing capabilities achieve superior performance. Additionally, the positive relationship between market orientation and competitiveness was confirmed, extending the findings of other studies by replication in an economically isolated and 
less developed context. Higher competitive performance also demands both strong competitive and entrepreneurial values. This suggests that in addition to marketing expertise and a market focus, competitiveness is best achieved through complementary values emphasizing market superiority and risk-taking.

Fiji presents a unique context for confirming the universality of the marketing concept. For example, the composition of organizational culture is more heavily weighted toward consensual and bureaucratic values and less so toward the competitive and entrepreneurial values that have a positive influence on firm competitiveness (see Table 1). This organizational value profile more closely resembles those found in transitional economies of China and Vietnam (Deshpandé \& Farley, 2004). Fiji does not have a history of a planned economy, which suggests there may be other macroenvironmental forces at work. Either way, these results would indicate an opportunity to increase organizational competitiveness for firms that develop these values. On the flip side, these results also suggest that global competition poses a significant threat to firms operating in Fiji, as these indigenous firms are on the whole weak in competitive and entrepreneurial values.

\section{Limitations and Future Research}

Although the study hypotheses are supported, it is important to note limitations. First, reliance on cross-sectional data warrants caution in interpreting the results. A second limitation is the reliance on single informants. While efforts were undertaken to ensure that respondents were qualified, biases may be introduced based on the selective perception of individual respondents. Additionally, a larger sample and more robust empirical method are needed to fully assess the measurement properties and structural effects.

This research presents multiple opportunities for increased understanding of the mechanisms that support the marketing concept and organizational competitiveness. First, the marketing concept, as contained within expertise, beliefs, and values, is a product of the organization's memory. The market-driven firm must maintain an accessible memory of past successes and failures (Day, 1994), which is retained by individuals and stored as organizational procedures, strategies, schemas, and culture. Research needs to further elucidate the organization's marketing memory and examine its impact on firm behavior, particularly those capabilities that allow a firm to more effectively configure resources in a changing environment (Eisenhardt \& Martin, 2000).

This study demonstrates that a marketing concept provides a route to competitiveness; however, there may be alternative paths to superior performance. While there is some evidence that a production orientation (i.e., focus on operational efficiencies) does not equate to firm success (Noble et al., 2002), future research might examine the efficacy of alternative orientations across economic contexts. Alternative orientations may, in fact, be complementary rather than separate ends of a continuum. Similarly, the current study focuses solely on marketing strategies whereby internal inputs are transformed into satisfying customer value; however, an alternative path for firms in less economically developed nations may be through different forms of outsourcing (Khan \& Ghani, 2004). Finally, this study assumes superior performance in terms of competitive rather than cooperative advantage (Lei et al., 1997). Under different conditions, cooperation, or some form of co-opetiton (Brandenbuger \& Nalebuff, 1996), may deliver superior returns.

The current study examines the performance effect of firm-specific factors in organizations operating in Fiji. Future research might examine institutional factors along with marketing and managerial systems in multiple economic and cultural contexts. For example, research could examine the influence of national culture on marketing concept manifestations, especially given that national and firm culture may be at odds. As noted by Shultz and Pecotich (1997), a nation's educational system may perform a key role in enabling "a comprehensive and competitive knowledge system" (p. 62), yet this remains an area in need of study. Similarly, institutional influence from multinational corporations may 
shape the adoption of the marketing concept among subsidiaries. Examining the adoption and efficacy of the market concept under different macroenvironmental conditions would further test the boundaries of this core marketing principle.

While this study focused on domestic competitiveness, research is needed that examines how marketing capabilities developed in domestic markets translate onto the global marketplace. Research should isolate how social, political, natural, technological, and economic forces influence firm-level characteristics. These broader forces provide the context upon which firm competitiveness contributes to the economic prosperity of nations (Porter, 1990; Snowdon \& Stonehouse, 2006). This line of inquiry would increase understanding of organizational competitiveness and promote economic development. To assess the impact of country-level cultural components, this research could be extended to look at the "marketing concept—competitiveness" relationship in other developing countries, including low-income countries. This would serve to validate this study's findings and provide an opportunity to reveal factors that are unique to each nation.

\section{CONCLUSION}

This study examines the prevalence of the marketing concept in firms operating in Fiji and identifies a means by which the marketing concept translates into organizational competitiveness. By exploring an underresearched population, this study clarifies and measures allusive yet critical marketing concept manifestations that lead to market success. These manifestations are contained within the interacting experiences, beliefs, and values that embody the marketing concept. For managers and future managers, this study provides an understanding of the market concept within an isolated and less economically developed context, which is necessary to transform organizations into competitive entities. The findings of this and future studies should be of value to the large segment of consumers in less economically developed countries who might benefit from greater competition, accelerated innovation, and increased customer choice.

\section{ACKNOWLEDGMENTS}

This project was supporting in part by a Center for International Business Education and Research Summer Fellowship provided by the University of Washington's Global Business Center. The study was conducted while the first author was a visiting lecturer at the University of the South Pacific.

\section{REFERENCES}

Baldacchino, G. (2000). An exceptional success: The case of an export-oriented, locally-owned, small-scale manufacturing firm in a small island country. Journal of Pacific Studies, 23(1), 27-47.

Bhuian, S. N. (1998). An empirical examination of market orientation in Saudi Arabian manufacturing companies. Journal of Business Research, 43(1), 13-25.

Brandenburger, A. M., \& Nalebuff, B. J. (1996). Coopetiton. New York: Doubleday.

Celly, K. S., \& Frazier, G. L. (1996). Outcome-based and behavior-based coordination efforts in channel relationships. Journal of Marketing Research, 33(2), 200210.

Day, G. S. (1994). The capabilities of market-driven organizations. Journal of Marketing, 58(4), 37-52.

Day, G. S., \& Wensley, R. (1988). Assessing advantage: A framework for diagnosing competitive superiority. Journal of Marketing, 52(2), 1-20.

Deshpandé, R., \& Farley, J. U. (2004). Organizational culture, market orientation, innovativeness, and firm performance: An international research odyssey. International Journal of Research in Marketing, 21(1), 322.

Deshpandé, R., Farley, J. U., \& Webster, F. E. (1989). Corporate culture, customer orientation, innovativeness in Japanese firms: A quadrad analysis. Journal of Marketing, 57(1), 23-37.

Eisenhardt, K. M., \& Martin, J. A. (2000). Dynamic capabilities: What are they? Strategic Management Journal, 21, 1105-1121.

Emmott, B. (1985). Fiji: Islands in the wind. The Economist, July 27, 33-40.

Hailey, J. M. (1985). Indigenous business in Fiji. Honolulu: Pacific Islands Development Program/East-West Center. 
International Monetary Fund. (2007). World Economic Outlook Database. Retrieved August 31, 2007, from http://www.imf.org/external/pubs/ft/weo/2007/01/data /index.aspx.

Khan, J. H., \& Ghani, J. A. (2004). Clusters and entrepreneurship: implications for innovation in a developing economy. Journal of Developmental Entrepreneurship, 9(3), 221-238.

Kirca, A. H., Jayachandran S., \& Bearden, W. O. (2005). Market orientation: a meta-analytic review of its antecedents and impact on performance. Journal of Marketing, 69(2), 24-41.

Kohli, A. K., \& Jaworski, B. J. (1990). Market orientation: The construct, research propositions, and managerial implications. Journal of Marketing, 54(2), 118.

Lei, D., Slocum, J. W., \& Pitts, R. A. (1997). Building cooperative advantage: Managing strategic alliances to promote organizational learning. Journal of World Business, 32(3), 203-223.

Liu, S. S., Luo, X., \& Shi, Y. (2003). Market-oriented organizations in an emerging economy: A study of missing links. Journal of Business Research, 56, 481491.

Lusch, R. F., \& Brown, J. R. (1996) Interdependency, contracting, and relational behavior in marketing channels. Journal of Marketing, 60(October), 19-38.

Netemeyer, R. G., Bearden, W. O., \& Sharma, S. (2003). Scaling procedures: Issues and applications. Thousand Oaks, CA: Sage Publications.

Noble, C. H., Sinha, R. K., \& Kumar, A. (2002). Market orientation and alternative strategic orientations: a longitudinal assessment of performance implications. Journal of Marketing, 66(4), 25-39.

Porter, M. E. (1990). The competitive advantage of nations. New York: Free Press.

Qalo, R. R. (1997). Small business: A study of a Fijian family: The Mucunabitu Iron Works Contractor Cooperative Society Limited. Suva, Fiji: Mucunabitu Education Trust.

Quinn, R. E., \& Rohrbaugh, J. (1983). A spatial model of effectiveness criteria: Towards a competing values approach to organizational analysis. Management Science, 29(3), 363-377.

Reddy, M. (2004). Enhancing competitiveness of Fiji's economy. In: Competitiveness strategies for small states. L. Briguglio and G. Cordina (editors). Malta: Formatek Ltd.

Reddy, N. (2001). General managers in the South Pacific. Aalborg, Denmark: Aalborg University Press.

Schein, E. H. (1992). Organizational culture and leadership (2nd ed). San Francisco: Jossey-Bass Publishers.

Shultz, C. J., \& Pecotich, A. (1997). Marketing and development in the transition economies of Southeast
Asia: Policy explication, assessment, and implications. Journal of Public Policy and Marketing, 16(1), 5568.

Schwartz, S. H. (2004). Mapping and interpreting cultural differences around the world. In Comparing cultures: Dimensions of culture in a comparative perspective (pp. 43-73), H. Vinken, J. Soeters \& P. Ester, eds. Liden, Netherlands: Brill.

Subramanian, R., \& Gopalakrishna, P. (2001). The market orientation-performance relationship in the context of a developing economy: An empirical analysis. Journal of Business Research, 53, 1-13.

Snowdon, B., \& Stonehouse, G. (2006). Competitiveness in a globalised world: Michael Porter on the microeconomic foundations of the competitiveness of nations, regions, and firms. Journal of International Business, 37, 163-175.

Teece, D. J., Pisano, G., \& Shuen, A. (1997). Dynamic capabilities and strategic management. Strategic Management Journal, 18, 509-533.

Trice, H. M., \& Beyer, J. M. (1993). The cultures of work organizations. Englewood Cliffs, NJ: PrenticeHall.

United Nations Development Programme. (2006). Human development report 2006: Beyond scarcity: Power, poverty and the global water crisis. New York: Palgrave Macmillan.

Van Gelder, J., De Vries, R. E., Frese, M., \& Goutbeek, J. (2007). Differences in psychological strategies of failed and operational business owners in the Fiji Islands. Journal of Small Business Management, 45(3), 388400.

Vorhies, D. W., \& Morgan, N. A. (2005). Benchmarking marketing capabilities for sustainable competitive advantage. Journal of Marketing, 69(1), 80-94.

Walsh, J. P., \& Ungson, G. R. (1991). Organizational memory. Academy of Management Review, 16(1), 5791.

White, J. C., Varadarajan, P. R., \& Dacin, P. A. (2003). Market situation interpretation and response: The role of cognitive style, organizational culture, and information use. Journal of Marketing, 67(3), 63-79.

World Bank. (2007). Data: Country groups. Retrieved August 31, 2007, from http://web.worldbank.org/servlets/ ECR? contentMDK=20421 402\& sitePK=239419.

Zollo, M., \& Winter, S. G. (2002). Deliberate learning and the evolution of dynamic capabilities. Organization Science, 13(3), 339-351. 


\section{APPENDIX 1. Scale Content and Source}

1. Organizational Competitiveness ${ }^{1}$ (adapted from Day \& Wensley, 1988; Lusch \& Brown, 1996)

For this set of questions you will assess your organization's performance over the last year relative to other's in your industry. Use the scale: 1 = Significantly worse performance than others in the industry and $7=$ Significantly better performance than others in the industry.

Sales growth

Profit growth

Overall profitability

Liquidity

Labor productivity

Cash flow

Product/service quality

Market share

Customer satisfaction

Delivering customer value

Customer loyalty

2. Marketing Expertise ${ }^{2,3}$ (adapted from Celly \& Frazier, 1996)

In deploying the capabilities above, my organization utilizes:

... a great deal of knowledge.

.... strong skills.

... developed skills and activities.

3. Market Orientation ${ }^{2}$ (Deshpandé \& Farley, 2004)

We have routine or regular measures of customer service.

Our product and service development is based on good market and customer information.

We know our competitors well.

We are more customer-focused than our competitors.

We have a good sense of how our customers value our products and services.

We compete primarily based on product or service differentiation.

The customer's interest should always come first, ahead of the owners.

Our products/services are the best in the business.

I believe this business exists primarily to serve customers.

4. Competing Values ${ }^{4}$ (Deshpande \& Farley, 2004)

a) Kind of Organization (Please distribute 100 points)

Points for A My organization is a Points for $\mathrm{B}$

personal place. It is like

an extended family.

People seem to share a

lot of themselves.

Points for $C$ My organization is a $\quad$ Points for $D$

formalized and

structured place.

Established procedures

generally govern what

people do.

b) Leadership (Please distribute 100 points)

Points for A The head of my

Points for $\mathrm{B}$

organization is

generally considered to

be a mentor, sage, or a

father or mother figure.

Points for $\mathrm{C}$ The head of my

Points for $\mathrm{D}$

organization is

generally considered to

be a coordinator, an

organizer, or an

administrator.

My organization is a

dynamic and

entrepreneurial place.

People are willing to

stick their necks out

and take risks.

My organization is a production oriented place. A major concern is with getting the job done, without much personal involvement.

The head of my organization is generally considered to be an entrepreneur, an innovator, or a risk taker.

The head of my organization is generally considered to be a producer, a technician, or a hard driver. 


\section{APPENDIX 1. Continued}

\author{
c) What Holds the Organization Together (Please distribute 100 points) \\ Points for $A$ \\ The glue that holds my \\ organization together is \\ loyalty and tradition. \\ Commitment to this \\ organization runs high. \\ Points for B
}

Points for $\mathrm{C}$

The glue that holds my organization together is formal rules and policies. Maintaining a smooth-running institution is important here.

d) What is Important (Please distribute 100 points) Points for $\mathrm{A}$

My organization emphasizes human resources. High cohesion and morale in the organization are important.

Points for $\mathrm{C}$
Points for D

(n)

Points for B

Points for D

emphasizes

permanence and stability. Efficient, smooth operations are important.

The glue that holds my organization together is a commitment to innovation and development. There is an emphasis on being first.

The glue that holds my organization together is the emphasis on tasks and goal accomplishment. A production-orientation is commonly shared.

My organization emphasizes growth and acquiring new resources. Readiness to meet new challenges is important.

My organization emphasizes competitive actions and achievement. Measurable goals are important.

Note. ${ }^{1}$ Seven-point much worse-much better-to others in industry.

${ }^{2}$ Seven-point agree-disagree scale.

${ }^{3}$ This set of items is proceeded by a list of marketing capabilities from Day (1994).

${ }^{4}$ Constant sum scale with the four organizational value types derived by adding the A items for consensual, B items for entrepreneurial, $\mathrm{C}$ items for bureaucratic, and $\mathrm{C}$ items for competitive. 